\title{
Hemodynamically significant atrial fibrillation in a previously healthy man with ethylene glycol toxicity
}

\author{
Ryan Thompson, Allan R. Mottram \\ Department of Emergency Medicine, University of Wisconsin, Madison, USA \\ Correspondence: Allan R. Mottram. Address: University of Wisconsin, Department of Emergency Medicine, 600 Highland \\ Ave, MC3280, Madison, WI 53792, USA. Email: armottram@medicine.wisc.edu
}

Received: January 20, 2014

Accepted: February 7, 2014

Online Published: February 18, 2014

DOI : $10.5430 /$ crim.v1n1p21

URL: http://dx.doi.org/10.5430/crim.v1n1p21

\begin{abstract}
Ethylene glycol ingestion is a well-described phenomenon that results in altered mental status, anion gap metabolic acidosis, and renal failure. Cardiac sequelae of ethylene glycol ingestion have not been well described in the literature. We report a case of a young, previously healthy man who developed atrial fibrillation successfully treated with electrical cardioversion in the setting of a large ethylene glycol ingestion with a late presentation.
\end{abstract}

\section{Key words}

Ethylene glycol, Metabolic acidosis, Atrial fibrillation, Toxicity

\section{I ntroduction}

Ethylene glycol ingestion is a well-described phenomenon that results in altered mental status, anion gap metabolic acidosis, and renal failure ${ }^{[1]}$. Cardiac sequelae of ethylene glycol ingestion have not been well described in the literature. We report a case of a young, previously healthy man who developed atrial fibrillation successfully treated with electrical cardioversion in the setting of a large ethylene glycol ingestion with a late presentation.

\section{Case presentation}

A 28-year-old man presented to a small rural emergency department by EMS after being found unresponsive in a snow bank. At the scene there was evidence of vomiting and incontinence of stool. During transport he received naloxone with no effect. The patient's medical history was remarkable only for a small traumatic subarachnoid hemorrhage after being hit by a car 4 years prior.

On arrival to the emergency department, he was noted to be obtunded, but spontaneously breathing with adequate oxygen saturations. The patient's initial vital signs were a blood pressure of 150/84, pulse rate 92, respiratory rate 14, pulse oximetry of $100 \%$. His Pupils were $3 \mathrm{~mm}$, equal, and sluggishly reactive to light. His skin was cool and dry. On neurologic examination, the patient was unresponsive to painful stimuli. 
Computed tomography imaging of the head without intravenous contrast was normal, without evidence of bleeding, swelling, or midline shift. Initial laboratory values revealed significant metabolic derangements including potassium of $6.9 \mathrm{mmol} / \mathrm{L}, \mathrm{pH}$ of 6.83, $\mathrm{pCO}_{2}$ of $11 \mathrm{mmHg}, \mathrm{HCO}_{3}$ of $1.9 \mathrm{mmol} / \mathrm{L}$, with an anion gap of 39. Initial toxicology screens including acetaminophen, salicylates, and alcohol were undetectable. Initial 12-lead electrocardiogram demonstrated sinus rhythm with peaked T-waves. The patient received calcium gluconate, insulin and glucose, furosemide, and nebulized albuterol for his hyperkalemia, and was endotracheally intubated without medications prior to emergent transfer via helicopter ambulance to a tertiary care facility. During transport he became hypertensive to a maximum of $180 / 100$, for which he was treated with midazolam. He also received 50 meq of sodium bicarbonate for his acidosis. Throughout transport, he remained in sinus rhythm without ectopy.

The patient arrived at the intensive care unit at time 1820. Repeat blood work on arrival revealed an arterial $\mathrm{pH}$ of 6.65 , $\mathrm{pCO}_{2}$ of $34 \mathrm{mmHg}, \mathrm{HCO}_{3}$ of $3.5 \mathrm{mmol} / \mathrm{L}, \mathrm{pO}_{2}$ of $259 \mathrm{mmHg}$, sodium of $146 \mathrm{mmol} / \mathrm{L}$, potassium of $6.2 \mathrm{mmol} / \mathrm{L}$, Chloride of $111 \mathrm{mmol} / \mathrm{L}, \mathrm{HCO}_{3}$ of $3.5 \mathrm{mmol} / \mathrm{L}$, BUN $18 \mathrm{mmol} / \mathrm{L}$, Creatinine of $1.16 \mathrm{mmol} / \mathrm{L}$, Glucose of $211 \mathrm{mmol} / \mathrm{L}$ (calculated anion gap of 31.5, calculated osmolality of $310 \mathrm{mOsm} / \mathrm{kg}$ ), measured serum osmolality of 370, (osmolar gap of 60). Liver function tests were unremarkable. A complete blood count revealed a leukocytosis of $34.5 \mathrm{~K} / \mathrm{uL}$, hemoglobin of $16.7 \mathrm{~g} / \mathrm{dL}$, hematocrit of 51\%, and platelets of $359 \mathrm{~K} / \mathrm{uL}$. He was hypothermic (axillary temperature of $34.6^{\circ} \mathrm{C}$ ), mildly tachycardic (102 beats per minute), with a stable blood pressure of 119/52. His initial ventilator settings on arrival to the ICU were PRVC mode, $100 \% \mathrm{FiO}_{2}$, rate 15 bpm, Tidal volume (TV) 500ml, and PEEP 5 mmHg.

Telemetry showed widening QRS duration, which was confirmed by 12-lead ECG, demonstrating sinus rhythm with a measured QRS of $142 \mathrm{~ms}$ (see Figure 1). Six $50 \mathrm{mEq}$ ampules of sodium bicarbonate were given between arrival and 1900. Rapid correction of QRS widening was evident on telemetry after each dose, and then progressive widening once more. Repeat ABG at time 1904 showed $\mathrm{pH}$ of 6.92, $\mathrm{pCO}_{2} 79, \mathrm{pO}_{2}$ 377, $\mathrm{HCO}_{3}$ of 15.2. His ventilator rate was increased to 24 bpm, TV increased to $600 \mathrm{ml}$, and $\mathrm{FiO}_{2}$ reduced to $50 \%$.

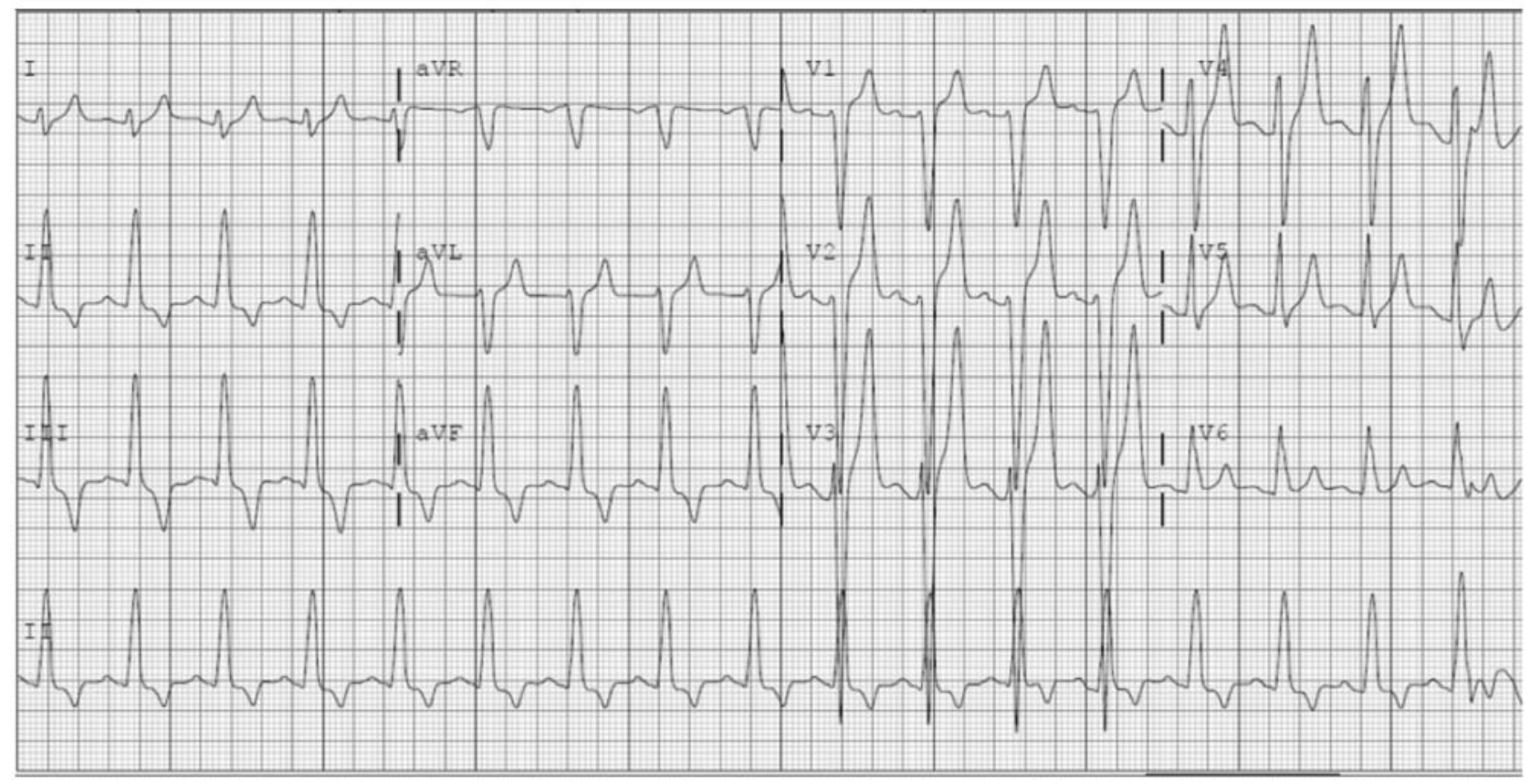

Figure 1. 12-lead ECG from arrival to ICU. Normal sinus rhythm with prolonged QRS of 142 ms.

A double lumen hemodialysis catheter was placed into the patient's right internal jugular vein at time 1920 . There was no ectopy noted during the procedure. The patient had an ethylene glycol level drawn which came back at time 1933 at 
$129 \mathrm{mg} / \mathrm{dL}$, with an undetectable methanol level. Fomepizole therapy was initiated at time 1944 at $15 \mathrm{mg} / \mathrm{kg}$. Between 1900 and initiation of dialysis at 1950, an additional 6 doses of $50 \mathrm{mEq}$ of sodium bicarbonate were given, and a bicarbonate drip at a rate of $80 \mathrm{mEq} / \mathrm{hr}$ was initiated.

At time 2015 (25 minutes after initiation of dialysis) the patient's BP deteriorated to 81/40, with a HR of $56 \mathrm{bpm}$. Norepinephrine drip was initiated, and rapidly titrated up to $0.5 \mathrm{mcg} / \mathrm{kg} / \mathrm{min}$. An additional $100 \mathrm{mEq}$ of sodium bicarbonate were given. Another $\mathrm{ABG}$ at 2035 showed $\mathrm{pH}$ of 7.28, $\mathrm{pCO}_{2}$ of 52, $\mathrm{pO}_{2}$ of 120, and $\mathrm{HCO}_{3}$ of 23.6. Electrolytes showed sodium of 160 , potassium of 3.9, chloride of 108 , BUN of 15 , creatinine of 0.96 (anion gap 26). The bicarbonate drip was stopped. Due to continually deteriorating blood pressures, the patient was started on vasopressin drip at 0.04 units/min at time 2100 .

At time 2120, the patient's rhythm deteriorated into atrial fibrillation with a heart rate of 133 . His blood pressure dropped from 91/52 to 83/52. 12-lead ECG confirmed the conversion of the rhythm to atrial fibrillation (see Figure 2).

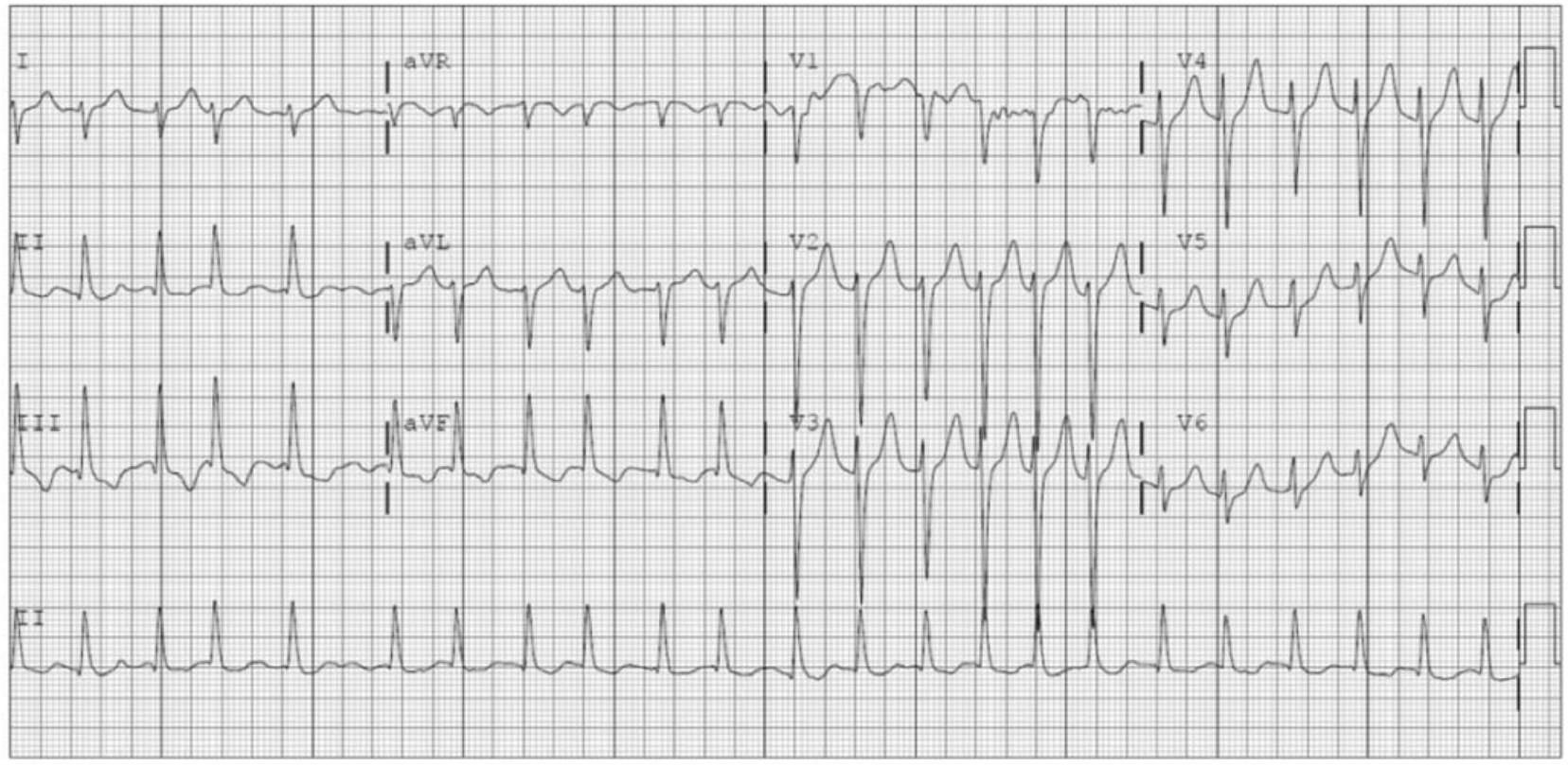

Figure 2. ECG taken when patient converted into atrial fibrillation with rapid ventricular response. There has been interval narrowing of QRS secondary to bicarbonate administration.

At time 2230, the patient was then given additional sedation with $150 \mathrm{mg}$ of ketamine. He was successfully cardioverted after 2 attempts, with the successful attempt utilizing $150 \mathrm{~J}$. His blood pressure improved to 98/64, and by 2300 his norepinephrine had been weaned to $0.36 \mathrm{mcg} / \mathrm{kg} / \mathrm{min}$. He remained in normal sinus rhythm for the remainder of his course. The patient continued on dialysis and fomepizole until his ethylene glycol level was reported at $22.2 \mathrm{mg} / \mathrm{dL}$ at time 0330 . He was extubated at 1000. The patient was weaned off of vasopressors by 1400 .

The patient had recovery of his mental status over the next 2 days. Further questioning of the patient revealed that he had ingested two large glasses of a green liquid the night before his admission (more than 18 hours prior to being found in the snow bank) after a friend told him that it was homemade whiskey. He was transitioned to general care on hospital day 4. He initially required intermittent hemodialysis, but within 9 days began to regain renal function. His creatinine peaked at 13.3. His hospital course was complicated by C. difficile diarrhea, but was otherwise unremarkable. He was discharged with no further dialysis requirement on hospital day 19. 


\section{Discussion}

In this case of severe metabolic acidosis caused by ethylene ingestion more than 18 hours prior to presentation, a young man with no history of cardiac arrhythmia developed a hemodynamically significant atrial arrhythmia necessitating electrical cardioversion. Multiple etiologies for this arrhythmia were considered. The patient had a very high level of ethylene glycol (approximately 5 times a toxic dose and more than 2 times the dose at which hemodialysis is recommended ${ }^{[1]}$ ). Autopsy data has shown oxalic acid crystal accumulation in multiple tissues, including the heart ${ }^{[2]}$. A prior forensic case report of an adult male with extremely high blood levels of ethylene glycol (greater than 20 times that of the case under discussion) in the absence of toxic metabolites indicated that he died as a direct result of unmetabolized ethylene glycol ${ }^{[3]}$. Unfortunately, it is not clear if the immediate cause of death was cardiac in nature, as a full autopsy was not performed. However, there is also no evidence suggesting that either ethylene glycol or its toxic metabolites are cardiotoxic or arrhythmogenic, and there are no prior case reports of atrial fibrillation following ethylene glycol ingestion with or without acidosis.

It is most likely that the patient's severe acidosis was the primary contributor to the development of atrial fibrillation. However, at the time the rhythm degenerated into atrial fibrillation, the $\mathrm{pH}$ had already climbed to at least 7.28. While there are no case reports in the literature of patients with ethylene glycol poisoning developing atrial fibrillation despite extremely severe acidosis (the most severe acidosis from ethylene glycol toxicity from which a patient is documented to have survived is $6.46^{[4]}$ ), there are multiple cases of toxic metabolic acidosis due to other poisons that have resulted in atrial fibrillation. One man developed atrial fibrillation with severe anion gap metabolic acidosis from ingestion of clenbuterol, a long-acting beta 2 agonist commonly found as an adulterant in heroin ${ }^{[5]}$. Another case of a man who died of chromated-copper-arsenate ingestion (a wood preservative) reported multiple premature atrial contractions prior to his degeneration into supraventricular tachycardia and then refractory ventricular fibrillation. He had a partially compensated metabolic acidosis on presentation ${ }^{[6]}$. Similarly, an Israeli man committed suicide by ingestion of a fluoro-silicate floor polish, presenting with bloody stools and severe metabolic acidosis and then degenerating into atrial fibrillation only very late in his course despite aggressive treatment with sodium bicarbonate ${ }^{[7]}$. Similar presentations of severe metabolic acidosis in the setting of toxic ingestion with late development of atrial fibrillation have been described from ingestions of sodium azide, boric acid, theophylline, and metformin ${ }^{[8-11]}$.

There were also several interventions that possibly could have contributed to the patient's arrhythmia. The patient received multiple doses of sodium bicarbonate, and was begun on a bicarbonate drip. This caused his acidosis to significantly improve (from a pH of 6.65 to 7.28 at the onset of atrial fibrillation) but also caused an iatrogenic hypernatremia. Hypernatremia has been associated with neurologic symptoms, but not with atrial fibrillation ${ }^{[12]}$. The patient was also on two vasopressors, norepinephrine and vasopressin, at the time of atrial fibrillation. The catecholamine effects of these medications may also have contributed to cardiac hyperstimulation.

Fomepizole has become the preferred antidote for ethylene glycol poisoning ${ }^{[1]}$, replacing IV ethanol. Fomepizole is not usually associated with cardiac sequelae. In one review of 174 patients being treated with either ethanol or fomepizole, there was only one cardiovascular adverse event, and that was an episode of bradycardia, not atrial dysrhythmia ${ }^{[13]}$.

While it is difficult to elucidate which of the above factors may have been the precipitating factor in the development of this patient's atrial fibrillation, it is nonetheless interesting to note the apparent rarity of atrial arrhythmia in ethylene glycol ingestion, as it has not been previously described.

\section{References}

[1] Mégarbane B, Borron SW, Baud FJ. Current recommendations for treatment of severe toxic alcohol poisonings. Intensive Care Med. 2005; 31:189-195. http://dx.doi.org/10.1007/s00134-004-2521-0 
[2] Leth PM, Gregersen M. Ethylene glycol poisoning. Forensic Science International. 2005; 155: 179-184. http://dx.doi.org/10.1016/j.forsciint.2004.11.012

[3] Garg U, Frazee C, Johnson L, Turner JW. A fatal case involving extremely high levels of ethylene glycol without elevation of its metabolites or crystalluria. Am J Forensic Med Pathol [Internet]. 2009; 30: 273-275. Available from:

http://journals.lww.com/amjforensicmedicine/pages/articleviewer.aspx?year=2009\&issue=09000\&article=00013\&type=abstract

[4] Blakeley KR, Rinner SE, Knochel JP. Survival of ethylene glycol poisoning with profound acidemia. New England Journal of Medicine. 1993; 328(7): 515-516. http://www.nejm.org/doi/full/10.1056/NEJM 199302183280717

[5] Bilkoo P, Thomas J, Riddle CD, Kagaoan G. Clenbuterol toxicity: an emerging epidemic. Conn Med. 2007; 71(2): 89-91.

[6] Hay E, Derazon H, Eisenberg Y, Natalia B. Suicide by ingestions of a CCA wood preservative. J Emerg Med. 2000; 19 (2): 159-63. http://dx.doi.org/10.1016/S0736-4679(00)00202-X

[7] Raikhlin-Eisenkraft B, Nutenko I, Kniznik D, Merzel J, Lev A. Death from fluoro-silicate in floor polish. Harefuah. 1994; 126(5): 258-9, 303.

[8] Albertson TE, Reed S, Siefkin A. A case of fatal sodium azide ingestion. J Toxicol Clin Toxicol. 1986; $24(4)$ : 339-51. http://dx.doi.org/10.3109/15563658608992598

[9] Restuccio A, Mortensen ME, Kelley MT. Fatal ingestion of boric acid in an adult. Am J Emerg Med. 1992; 10(6): 545-7. http://dx.doi.org/10.1016/0735-6757(92)90180-6

[10] Filejski W, Kurowski V, Batge B, Mentzel H, Djonlagic H. The clinical course and therapy of massive theophylline poisoning. Dtsch Med Wochenschr. 1993; 118(46): 1641-6. http://dx.doi.org/10.1055/s-2008-1059496

[11] Jurovich MR, Woolridge JD, Force RW. Metformin-associated nonketotic metabolic acidosis. Ann Pharmacother. 1997; 31(1): 53-5.

[12] Adrogue HJ, Madias NE. Hypernatremia. N Engl J Med. 2000; 342, 20: 1493-9. http://dx.doi.org/10.1056/NEJM200005183422006

[13] Lepik KJ, Levy AR, Sobolev BG, Purssell RA, DeWitt CR, Erhardt GD, et al. Adverse Drug Events Associated With the Antidotes for Methanoland Ethylene Glycol Poisoning: A Comparison of Ethanol and Fomepizole. Annals of Emergency Medicine. 2009; 53(4): 439-450. http://dx.doi.org/10.1016/j.annemergmed.2008.05.008 